\title{
ARQUEOLOGÍA Y PAISAJE EN EL INTERFLUVIO DE ZAPATA, CATAMARCA, NOROESTE ARGENTINO
}

\author{
ARCHAEOLOGY AND LANDSCAPE IN THE INTERFLUVE OF ZAPATA, \\ CATAMARCA, NORTHWESTERN ARGENTINA
}

\author{
Reinaldo Moralejo
}

Los lugares de tránsito han sido una constante en la historia de la humanidad. Independientemente de las formas y características que adopten, constituyen un elemento de comunicación cuyo estudio nos permite conocer la historia de las poblaciones que habitan un lugar determinado. En este artículo se presentan los resultados de las investigaciones realizadas en la sierra de Zapata, Catamarca (Noroeste Argentino), en una ruta que comunica los valles de Hualfín y Abaucán. Este espacio internodal o interfluvio serrano presenta un conjunto de sitios con diversas características que señalan un tránsito regional continuo desde épocas preincaicas.

Palabras clave: caminos antiguos, preincas, incas, El Shincal de Quimivil.

Places of transit have been constant in the history of humanity. Regardless of the forms and characteristics they adopt, places of transit constitute an element of communication whose study allows us to know the history of the populations that inhabit a given space. This article presents the results of research carried out in the mountains of Zapata, Catamarca (Northwestern Argentina), on a route that connects the Hualfín and Abaucán valleys. This internodal, interfluvial space includes several sites with diverse characteristics that indicate a continuous regional transit from pre-Inca times.

Keywords: ancient roads, pre-Inca, Inca, El Shincal de Quimivil.

\section{INTRODUCCIÓN}

La sierra de Zapata constituye un sistema serrano ubicado entre los valles de Hualfín y Abaucán en el centro de la Provincia de Catamarca, Noroeste Argentino (NOA). Se caracteriza por ser un área de interfluvio con un constante movimiento de personas y objetos, propio de zonas internodales (Raffino et al. 2008).

La historia de las investigaciones arqueológicas en el área se remonta a la segunda mitad del siglo xx con los aportes de Sempé $(1973,1976)$ y González y Sempé (1975), que dejan en evidencia el conjunto de asentamientos prehispánicos correspondientes al Período Temprano y Medio del NOA (500 AC-900 DC). Estos trabajos, sin embargo, estuvieron concentrados principalmente en el sector suroccidental de la sierra de Zapata, próximo a la localidad de Tinogasta del valle de Abaucán. Por esta razón, desde comienzos de la década de los noventa, en el marco de los proyectos dirigidos por el Dr. Rodolfo Raffino, se comenzó a prospectar el área a partir del derrotero inca que provenía desde el sitio El Shincal de Quimivil. Ello condujo a contar con otras evidencias arqueológicas vinculadas, por ejemplo, con el hallazgo de un tambo incaico denominado Tambillo de Zapata ubicado a media jornada de viaje entre los sitios de El Shincal y Watungasta (Raffino et al. 1994; Raffino 1995).

A Reinaldo Moralejo, División Arqueología, Museo de La Plata. ConiCET-Argentina. Facultad de Ciencias Naturales y Museo, Universidad Nacional de La Plata. Av. Paseo del Bosque s/nº, CP: B1900FWA, La Plata, email: reinaldomoralejo@yahoo.com.ar 
Posteriormente, debido al avance de los trabajos de puesta en valor en El Shincal, cesan las investigaciones en la sierra de Zapata hasta que son retomadas en el año 2004, con el propósito de complementar y ampliar los estudios realizados hasta ese momento.

En este artículo se presentan los resultados de las investigaciones llevadas a cabo en el área internodal o interfluvio de la sierra de Zapata desde un enfoque micro y macromorfológico. Se describen, por un lado, los elementos de construcción de las vías y, por otro, la información acerca de la configuración global del sistema vial. La relevancia de este trabajo reside en la incorporación de nuevas evidencias arqueológicas de antiguos caminos y sitios asociados que permiten comprender la importancia que tuvo esta ruta en la comunicación de los valles de Hualfín y Abaucán del centro oeste de la provincia de Catamarca, NOA. Una comunicación que, si bien puede extenderse desde momentos preincaicos hasta la actualidad, tuvo quizás su apogeo durante el momento de expansión incaica, al conectar el centro político, administrativo y ceremonial de El Shincal de Quimivil con la porción más meridional del Kollasuyu en Argentina y Chile. De esta manera, se pudo dar cuenta de la propia lógica interna de la red vial y de su contexto significativo, como también generar un modelo de organización respecto de las prácticas y relaciones sociales que dieron origen al paisaje.

\section{EL ESTUDIO DE LOS CAMINOS}

El Estado Inca se desarrolló a lo largo de la cordillera de los Andes en Sudamérica, desde el sur de Colombia (Departamento de Nariño) hasta la Región Central de Chile (Región del Maule) y Mendoza en Argentina (valle de Uspallata).

La red vial constituyó uno de los principales elementos integradores del Estado y permitió sostener un complejo sistema político, administrativo, militar y religioso. Abarcaba más de $40.000 \mathrm{~km}$ de caminos, convirtiéndose en el sistema vial más alto del planeta que logró alcanzar tal magnitud en un lapso menor a los cien años. La elección del espacio para su construcción no era producto del azar, sino más bien de la ideología y de un profundo conocimiento de la geografía e interacción social con el medio ambiente. Este sistema infraestructural de caminos favoreció la articulación en el interior y entre las diferentes poblaciones que habita- ban en las zonas altas y bajas de los Andes centrales y meridionales, permitiendo la movilización de diversos tipos de productos, poblaciones (mitimaes), ejércitos y dirigentes de alto rango jerárquico, entre otras cosas (Hyslop 1992; Vitry 2000).

De acuerdo al planteo de Anschuetz et al. (2001), las comunidades transforman los espacios físicos en lugares llenos de contenidos mediante sus actividades diarias, sus creencias y sus sistemas de valores. Como consecuencia, un paisaje no es meramente el mundo que vemos, es una construcción, una composición de ese mundo. Desde esta perspectiva, los espacios físicos de un paisaje no son mudos en cuanto a la historia de la comunidad y a su herencia cultural; son una interacción dinámica entre naturaleza y cultura. Se asume entonces que la acción social que tiene lugar en relación con el espacio está organizada de manera coherente según el sistema de representaciones propio del grupo social que la realiza. De este modo, la importancia de estudiar los caminos radica en que a través de ellos se construye y se expresa la memoria de los pueblos que los transitan, los elaboran y les dan significado a lo largo del tiempo y del espacio. Creemos entonces que recorriendo y estudiando los caminos podemos aproximarnos al conocimiento de la heterogeneidad social de las poblaciones que habitan y circulan un lugar determinado (Moralejo \& Aventín Moretti 2015).

Por otra parte, cuando se habla del estudio de los caminos no se trata solo de los caminos per se sino también del conjunto de sitios arqueológicos y elementos del paisaje asociados. El movimiento y la percepción a través del paisaje permiten producir y reproducir diferentes conjuntos de significaciones que podrían estar materializadas en el paisaje. De este modo, la presencia de apachetas, mojones, rocas sagradas, lugares de libación $\mathrm{u}$ ofrendas, cuerpos de agua, puestos de observación, tambos, chasquihuasis, los diferentes tipos de trazados, anchura, puentes, rampas, entre otros, le confieren al paisaje vial un significado geográfico y ritual que va mucho más allá del simple tránsito.

En el lenguaje arqueológico existe una amplia variedad de palabras que se utilizan para designar a un lugar o zona de tránsito determinada. El término genérico de vía designa cualquier curso de tránsito humano físicamente visible en el terreno, independientemente de sus características. Por otro lado, el término ruta se usa como equivalente de itinerario o derrotero de un viaje, siendo entonces una categoría abstracta o intangible. 
En este sentido, "una ruta puede tener ya sea trazas separadas o traslapadas de varias vías de una misma o diferente naturaleza o época" (Berenguer et al. 2005: 14).

Existen dos tipos de vías: los caminos y los senderos. Un camino es una vía formal que presenta evidencias significativas de planeamiento y construcción. Por otro lado, un sendero constituye una vía informal caracterizada por no poseer, o apenas poseer, un trabajo dirigido hacia su elaboración o mantenimiento. Son producto del desgaste a raíz del continuo movimiento de personas, y en algunos casos de animales, a través del paisaje (Earle 1991; Trombold 1991).

En la práctica, no es sencillo diferenciar caminos y senderos. Existe una amplia variedad de vías producto de la superposición y el cambio en los patrones de interacción y planificación. Por lo tanto, los caminos pueden transformarse en senderos y viceversa (Earle 1991).

En el caso de la sierra de Zapata, los estudios de Sempé $(1973,1976)$ y González y Sempé (1975), aun cuando no mencionan la presencia de caminos o senderos antiguos, ponen en evidencia un corpus de datos que nos permiten inferir posibles comunicaciones entre los valles de Hualfín y Abaucán durante momentos preincas. Por lo tanto, consideramos importante contemplar en nuestra investigación todo el conjunto de vías preincaicas, incaicas y aquellas que continuaron siendo utilizadas en épocas colonial y republicana, hasta incluso la actualidad.

\section{METODOLOGÍA}

Nuestra investigación sobre los caminos incaicos se desarrolló en un marco espacial local y regional y se centró en la descripción de los procesos socioculturales que condujeron a la construcción del paisaje en la sierra de Zapata. Para conocer el conjunto de elementos que constituyen el paisaje social de una red vial, fue necesario definir los procesos de formalización a través de los cuales se configura la cultura material arqueológica. Para ello se diseñó una estrategia de investigación basada en dos enfoques metodológicos complementarios (Moralejo 2011):

a) Estudio micromorfológico. Consistió en un análisis particularista en que se registraron todos los rasgos relacionados con la construcción de una vía, tales como anchura, rectitud, características de la superficie, presencia de obras viales y otros rasgos como puntos de conexión con otras vías, asentamientos laterales de apoyo, montículos artificiales de piedra y presencia de objetos materiales en superficie (Trombold 1991).

b) Estudio macromorfológico. Consistió en un análisis regional tendiente a explorar la configuración global del sistema vial dentro del área de estudio y zonas aledañas. De esta manera, se registró información vinculada con la extensión de la red, función y temporalidad de los puntos conectados (Trombold 1991).

Esta estrategia de investigación combinó el análisis de cartas geológicas y topográficas, fotografías aéreas e imágenes satelitales, toponimia local, fuentes históricas y etnohistóricas, antecedentes bibliográficos, entrevista a pobladores, prospecciones y excavaciones arqueológicas.

El diseño de prospección fue de tipo pedestre e intensivo, con la intención de cubrir tanto la vía como las lomadas y los cerros adyacentes. Se diseñó un formulario ad hoc para sistematizar y ordenar toda la información recabada durante la prospección. Para su aplicación, se tomó el concepto de "punto de interés" utilizado para la descripción de caminos en el norte chileno: "un lugar donde la vía cambia de aspecto o de visibilidad, una cuesta o terreno en pendiente, un cruce o traslape con otra vía, una conexión vial, un lugar donde hay uno o más montones artificiales de piedras, un hallazgo de fragmentos cerámicos, un asentamiento o cualquiera otra estructura adyacente al camino" (Berenguer et al. 2005: 15).

Toda la etapa de prospección siempre estuvo acompañada de un mapa base que permitió cotejar los puntos y rasgos lineales marcados en gabinete con la información de terreno. El instrumental utilizado para el registro y medición consistió en: GPS configurado con Datum WGS84 y coordenadas planas UTM; cámara digital; brújula geológica Brunton; cinta métrica; jalones y Estación Total para realizar levantamientos arqueológicos en detalle. Durante la prospección también se practicaron recolecciones sistemáticas de material superficial en los puntos de interés respectivos. El objetivo de esta tarea era aproximarse a la cronología, uso y actividades en las vías. En el caso de los asentamientos arqueológicos, cada uno fue tratado de manera particular en conjunto con la fase de excavación.

Con toda la información recabada se elaboró un Sistema de Información Geográfica (SIG) en el que se volcaron las coordenadas de los puntos de interés y los segmentos de caminos identificados. 


\section{EL PAISAJE REGIONAL DEL ÁREA DE ESTUDIO}

La sierra de Zapata comprende el sector central de la provincia de Catamarca, NOA. Pertenece al sistema de sierras pampeanas noroccidentales con alturas que van de 2.000 a $3.000 \mathrm{msnm}$ y una orientación de noreste a suroeste (Morlans 1995). Se encuentra limitada al norte por el cordón de Los Colorados, al noreste por las serranías del Shincal y Belén, al este por el campo de Belén-Andalgalá o bolsón de Pipanaco, al oeste por el cordón y río de Las Lajas y la sierra de Fiambalá, y al sur por la sierra de Vinquis. Según Raffino et al. (2008), corresponde a un área de interfluvio -intermedia- entre dos grandes valles catamarqueños caracterizados por procesos sociales muy significativos para el NOA: Hualfín y Abaucán (fig. 1).

El clima del área es seco, principalmente hacia el occidente de la sierra. Sin embargo, existe un conjunto de condiciones microclimáticas locales determinadas por factores orográficos que provocan mayor pluviosidad y que constituyen el asiento de las principales actividades antrópicas (Morlans 1995).

El río Quimivil es el curso principal que alimenta la región. Es de carácter permanente y corre por el límite norte y noreste de la sierra de Zapata. El uso antrópico actual de este río consiste principalmente en el riego y el abastecimiento de agua para la población.

Otros cursos de agua importantes para la región son aquellos que descienden sobre la falda oriental de la sierra de Zapata hasta insumirse en los llanos del campo de Belén. La mayoría son de carácter temporario, incluso durante la temporada de lluvias (noviembre a marzo). Entre ellos, se destacan: el río La Aguada o Vallecito y el río El Tambillo o Piscuyacu, que desciende desde el portezuelo de la cuesta de Zapata casi paralelo a la antigua Ruta Nacional N ${ }^{\circ} 40$.

Las comunidades vegetales del área de estudio corresponden a las Provincias fitogeográficas del Monte y Prepuneña pertenecientes al Dominio Chaqueño (Región Neotropical). Dentro del Monte se destaca la presencia del Monte Espinoso sobre la parte apical de los conos aluviales de la ladera meridional de la sierra de Belén y oriental de la sierra de Zapata. El mismo está conformado por un bosque abierto con arbustal espinoso caducifolio (1.250 a $1.500 \mathrm{msnm}$ ) y bosques sobre franjas estrechas de quebradas de ríos permanentes (Capparelli 1997).
En cuanto a la Provincia Prepuneña (1.900 a 3.100 msnm), ha sido reconocida como ecotono Monte-Puna y se caracteriza por la presencia de cardonales y chaguarales dispuestos a manera de islotes sobre los faldeos de los cordones montañosos y la loma de los cerros más bajos (Morlans 1995; Moralejo 2011).

\section{EL SHINCAL DE QUIMIVIL, UNA CAPITAL INCAICA EN EL NOROESTE ARGENTINO}

El Shincal de Quimivil es un sitio incaico ubicado en el NOA perteneciente a la porción sur del Tawantinsuyu conocida como Kollasuyu. Se localiza a $5 \mathrm{~km}$ de la localidad de Londres (Departamento de Belén, Provincia de Catamarca), sobre el piedemonte de la serranía del Shincal a una altura de $1.350 \mathrm{msnm}$. El acceso al lugar se efectúa a través de un camino municipal que se empalma desde la antigua Ruta Nacional $N^{\circ} 40$, una de las más importantes de la República Argentina.

La primera descripción y el primer croquis del sitio fueron elaborados por Hilarión Furque (1900). Luego continúan los trabajos de Bruch (1911), quien realiza algunas exploraciones en el pueblo de Londres haciendo referencia a las ruinas arqueológicas allí emplazadas. En al año 1925, Wladimir Weiser y Friedrich Wolters, en el marco de las expediciones de Benjamín Muniz Barreto, realizan un breve pero excelente reconocimiento de campo en la zona del Shincal y alcanzan a describir una serie de conjuntos arquitectónicos (ushnu y kallankas) con características muy particulares (Moralejo et al. 2015). Posteriormente, en la década de los cincuenta, Alberto Rex González excava un conjunto residencial denominado "ruinas de Simbolar", actualmente conocido como Casa del Curaca o Sector "Alvis" (González 1966).

Desde fines de la década de los setenta, el Dr. Rodolfo Raffino comienza sus investigaciones en la zona, principalmente en los sectores medio y meridional del valle de Hualfín, la sierra de Zapata y la precordillera del occidente de Catamarca. Las mismas se prolongan hasta la actualidad y son dirigidas por varios de sus discípulos.

El paisaje de El Shincal es muy particular y se caracteriza por la presencia de algarrobos, chañares, acacias, talas y shinkis desarrollados entre los ríos Quimivil y Hondo. El área de ocupación supera las 30 ha y está compuesta por diversos edificios y/o estructuras que en conjunto conforman un patrón ortogonal que ha sido concebido, planeado y construido de acuerdo 


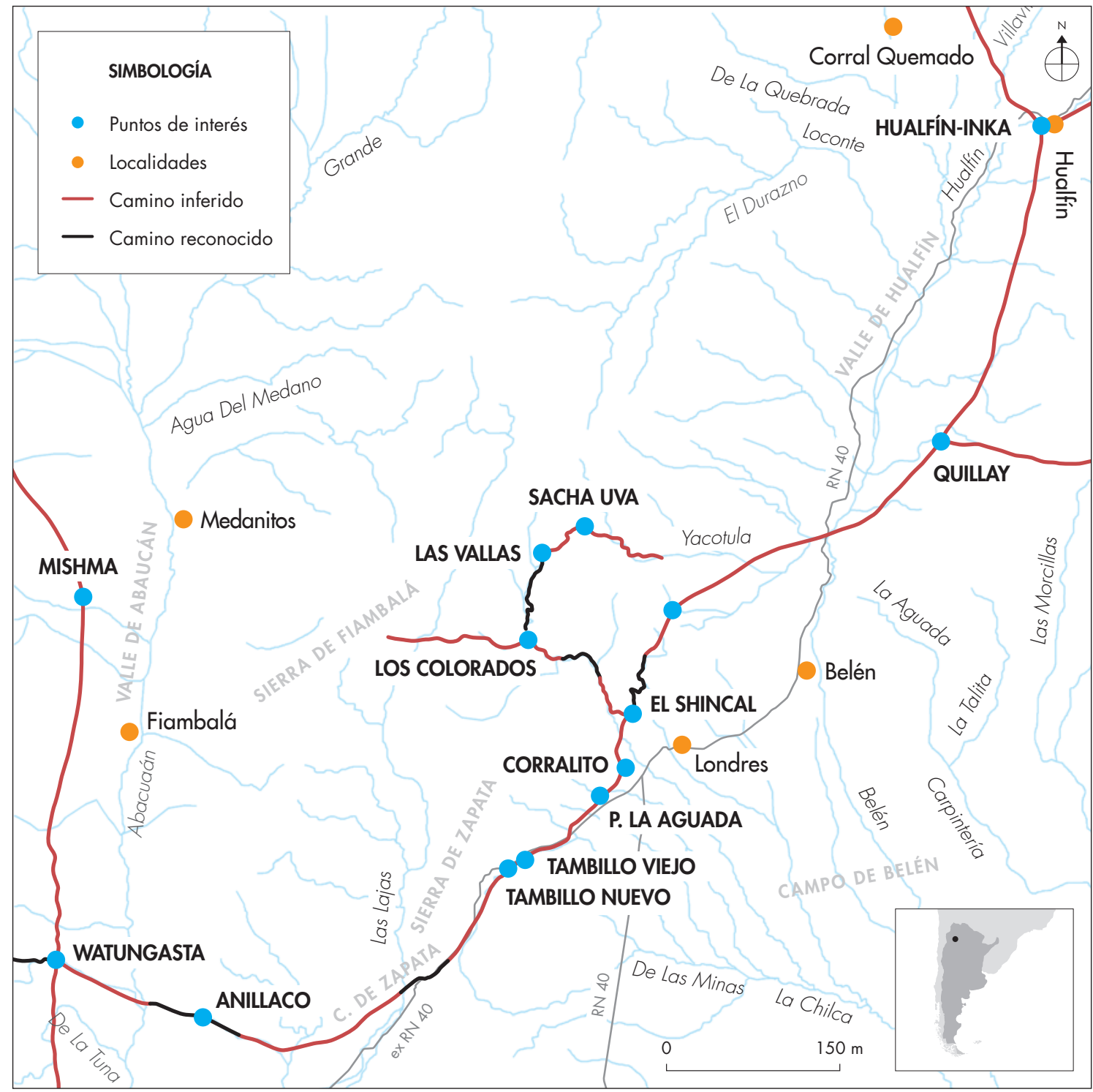

Figura 1. Área de estudio correspondiente a la sierra de Zapata. Figure 1. Area of study, Zapata hills.

al modelo incaico para sus centros administrativos regionales (Raffino 1995-1996, 2004) (fig. 2). En tal sentido, y teniendo en cuenta que este modelo cultural es semejante al observado en otros sitios incas de los Andes centrales, se ha pensado que El Shincal replicaba simbólicamente la capital del Tawantinsuyu, razón por la cual constituía un "Nuevo Cuzco" (Raffino 1990; Farrington 1999, 2013).

La importancia del sitio dentro del Kollasuyu ha sido tal que, de acuerdo a las evidencias materiales arqueológicas e históricas, pudo constituir el lugar donde
Pérez de Zurita fundara Londres de la Nueva Inglaterra en 1558 (Igareta 2008, 2009).

Entre los principales componentes de su planta urbana se destaca una gran plaza amurallada o aukaipata, en cuyo centro se encuentra el ushnu o plataforma ceremonial. Alrededor de la aukaipata existen grandes edificios rectangulares llamados kallanka (K1, K2, K3, $\mathrm{K} 4$ y K5), donde se realizaban diversas actividades políticas, administrativas y ceremoniales.

También existen diversos conjuntos residenciales con un formato regular -sujetos a algunas variaciones- 


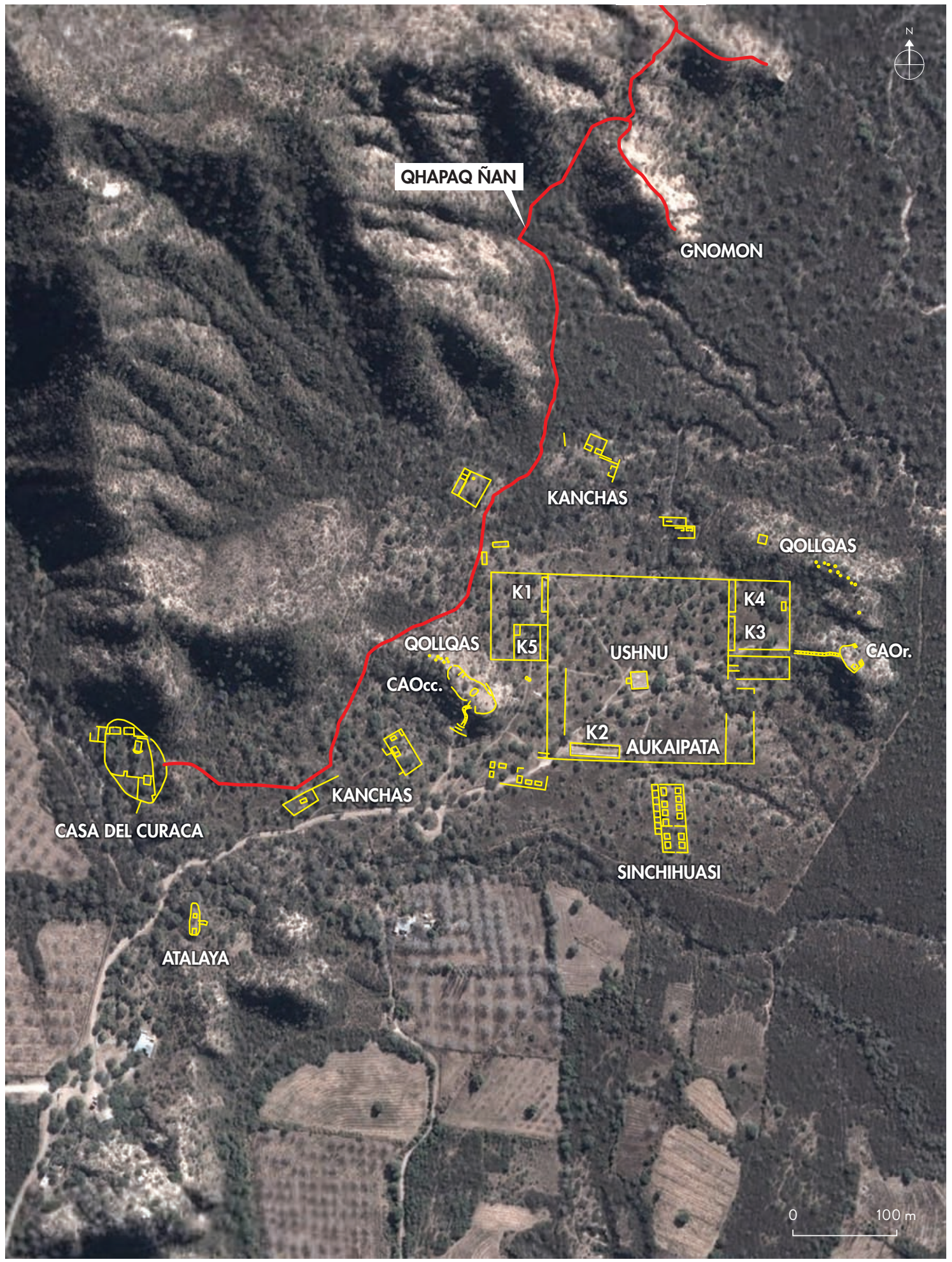

Figura 2. Plano del sitio El Shincal de Quimivil. Figure 2. Map of site El Shincal de Quimivil. 
conocidos como RPC (Rectángulo Perimetral Compuesto) o kancha. Estas unidades se encuentran dispuestas en torno a la aukaipata y, algunas de ellos, a la vera del camino incaico. Uno de estos conjuntos, denominado Casa del Curaca o sector "Alvis", estaba destinado a los gobernantes o la élite y se localizaba de modo aislado hacia el oeste del sitio. Otro, denominado sinchihuasi, alojaba a los habitantes que se encargaban de mantener el sitio a lo largo del año. Las demás podían constituir residencias permanentes y alojar a los invitados que arribaban a los eventos festivos durante determinadas épocas del año.

Existe otra kancha localizada hacia el suroeste del sitio, sobre la vera del camino incaico, que de acuerdo a las investigaciones que estamos realizando podría haber funcionado como una kancha templo. Hacia el suroeste del sitio y sobre una colina aterrazada se encuentra un conjunto de dos estructuras idénticas, enfrentadas entre sí. Según Farrington (2013), estarían replicando la forma de determinados templos existentes en el área cusqueña. En la figura 2 se puede observar este conjunto con el nombre de Atalaya. ${ }^{1}$

Otro aspecto interesante a destacar es la presencia, hacia el oriente y occidente de la aukaipata, de dos cerros aterrazados (CAOr. y CAOcc.) de $25 \mathrm{~m}$ de altura cuya cima se encuentra aplanada, y que quizás sirvieron para prácticas relacionadas con el culto solar. En la cima del Cerro Aterrazado Occidental se encuentra una gran roca cuya superficie imita la forma de los cerros tutelares que dominan el paisaje de El Shincal. También se han encontrado algunas oquedades que pudieron actuar como lugares para ofrendas y/o marcadores espaciales astronómicos. Esto último también ha sido observado en otros cerros vecinos, como el Cerro Loma Larga y el Cerro Divisadero, ubicados hacia el sur y suroeste del sitio, respectivamente.

En relación con la actividad administrativa y ceremonial, se han encontrado más de cincuenta estructuras de almacenamiento o depósitos llamados qollqas y varias rocas con unidades de molienda asociadas con la fabricación de alimentos y bebidas (Capparelli 1997; Giovannetti 2009), como también algunos entierros humanos (Raffino 2004).

Otro elemento de importancia es la presencia de un Gnomon o Intihuatana, situado a $460 \mathrm{~m}$ hacia el norte del ushnu, donde se cree que los incas realizaban observaciones solares (Farrington 1999, 2013).

\section{El camino de El Shincal}

El camino incaico que recorre la sierra de Zapata lo hace en sentido noreste-suroeste, conectando el valle de Hualfín, el pequeño valle de El Shincal, la quebrada del río El Tambillo y el valle de Abaucán.

El camino ingresa a El Shincal por el sector noreste atravesando un denso bosque espinoso que yace sobre el piedemonte oriental de la serranía homónima. La superficie del trazado es irregular, combinando pendientes cuesta arriba y cuesta abajo con pendientes laterales (Hyslop 1992). Su ancho varía entre $0,50 \mathrm{~m}$ y $2 \mathrm{~m}$ y se caracteriza por la presencia de diferentes rasgos estructurales que indican una determinada planificación y construcción vial. Se han identificado diferentes categorías de caminos, algunas de las cuales pueden encontrarse combinadas entre sí: despejado y amojonado; con muros de protección; con talud (o muro de contención); con talud y excavación dentro de la ladera (fig. 3a); con presencia de rampas; con presencia de escalonados y sistemas de drenaje. A estos tipos de caminos se suma también la presencia de sendas como un rasgo informal (Moralejo 2011).

Otra particularidad a resaltar es la asociación del camino con determinados sectores del bosque libre de vegetación, grandes rocas tokankas (fig. 4), almacenes qollqas y varios conjuntos habitacionales kancha. Entre estas últimas se destaca el conjunto correspondiente a la Casa del Curaca.

Las investigaciones en la Casa del Curaca han planteado su importancia como lugar de residencia de la élite dirigente teniendo en cuenta su localización, rasgos arquitectónicos y tipos de alfarería recuperada (González 1966; Raffino 2004; Giovannetti et al. 2012). Asimismo, los estudios de vialidad proponen la existencia de una trifurcación de caminos (Moralejo 2011): (a) uno en dirección noreste hacia el valle de Hualfín a través de la serranía del Shincal, y que ha sido descrito en esta sección; (b) otro en dirección suroeste hacia Watungasta a través del interfluvio de Zapata, que describiremos a continuación (fig. 3b); (c) otro secundario o transversal en dirección noroeste, aguas arriba del río Quimivil, hacia los enclaves de producción agrícola y pastoreo de Los Colorados y Las Vallas, del cual, por razones de espacio, no nos ocuparemos en este artículo. 

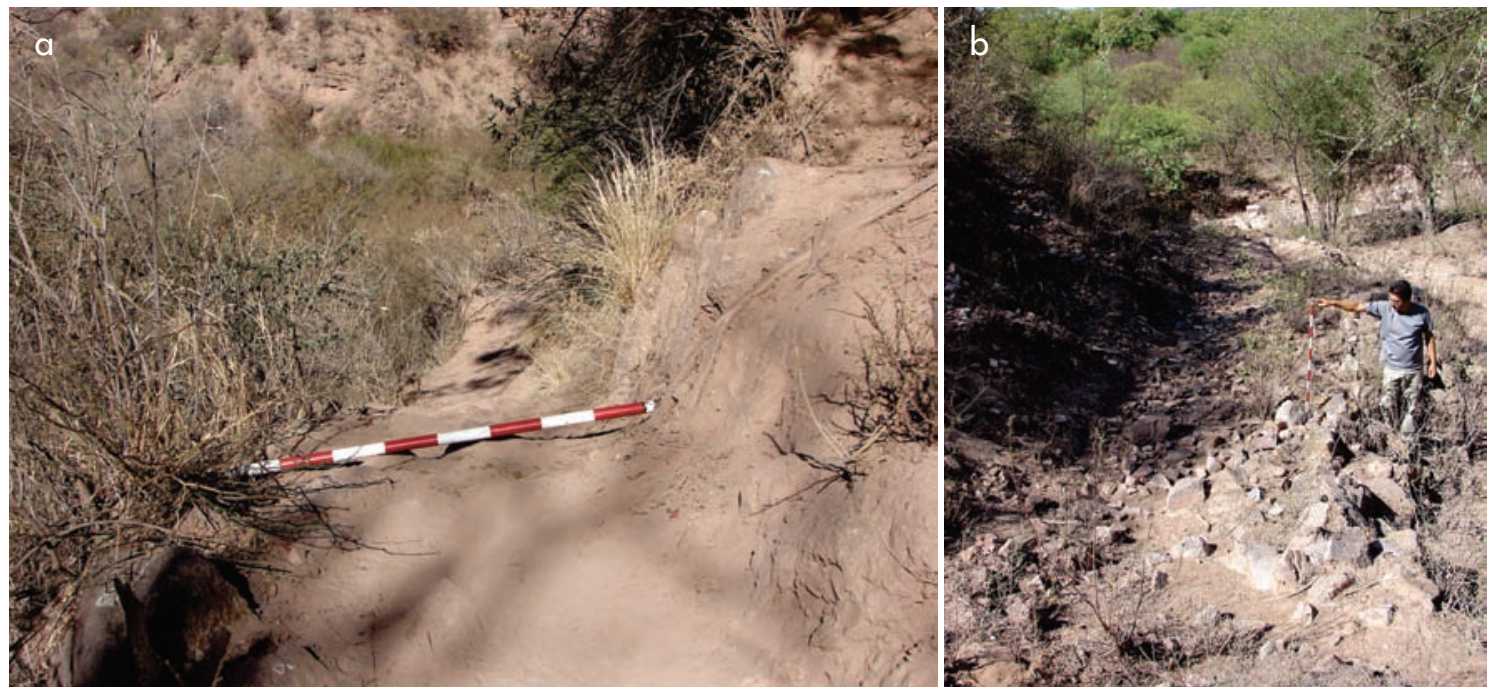

Figura 3: a) segmento de camino con talud y excavación dentro de la ladera; b) segmento de camino con talud, muro de protección y excavación ladera adentro correspondiente a la Casa del Curaca. Figure 3: $\boldsymbol{a}$ ) road segment with scree and excavation in the hillside; $\boldsymbol{b}$ ) road segment with scree, protection wall and in-hillside excavation, Casa del Curaca.
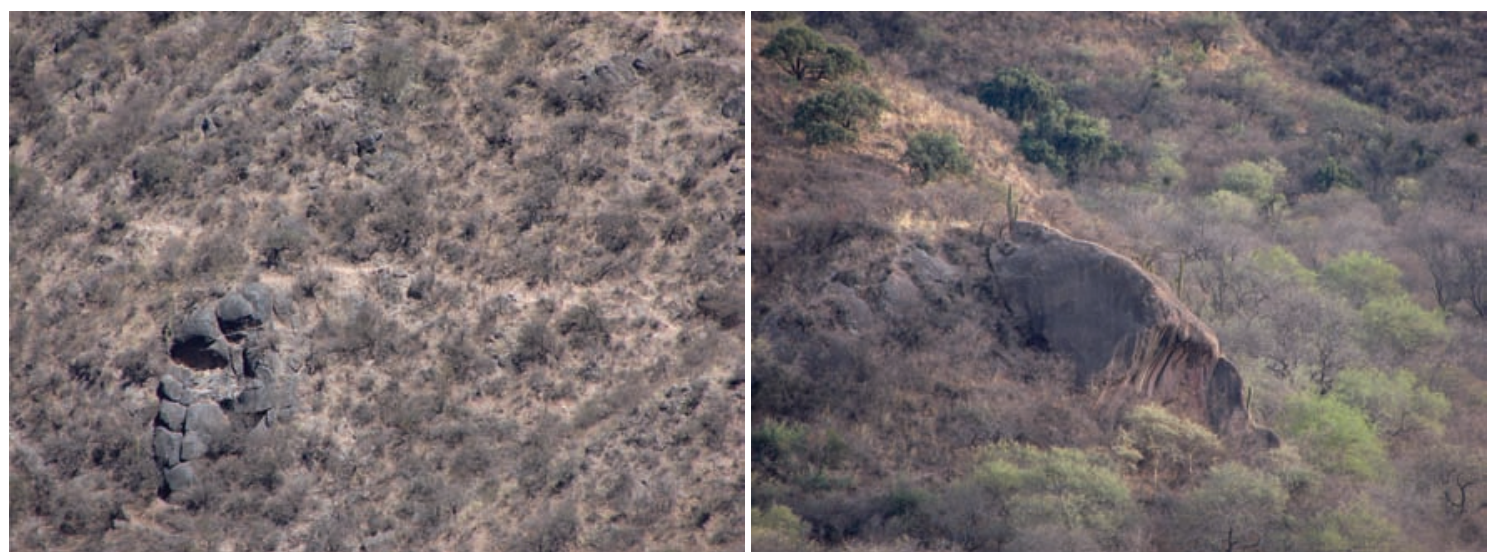

Figura 4. Grandes rocas a la vera del camino conocidas como "tokankas". La de la derecha ha sido denominada Piedra Negra (tomada de Moralejo \& Aventín Moretti 2015: 119, figura 6). Figure 4. Large roadside rocks known as tokankas. The one of the right has been named Piedra Negra (in Moralejo \& Aventín Moretti 2015: 119, Figure 6).

\section{LA RUTA A TRAVÉS DE LA SIERRA DE ZAPATA}

Anteriormente dijimos que desde la Casa del Curaca de El Shincal derivaba un camino en dirección suroeste con destino a Watungasta en el valle de Abaucán. Este camino se pierde inmediatamente a la salida del sitio debido a los efectos provocados por la alta ruralización y urbanización. Ello condujo a que la reconstrucción del derrotero incaico fuera dificultosa (para más detalles, véase Moralejo 2011). Por otra parte, las entrevistas a los pobladores locales dejaron entrever la existencia de un antiguo "carril del Inca" que conectaba El Shincal y la región de Abaucán pasando por los sitios de Corralito, Paraje La Aguada, Tambillos de Zapata y Cuesta de Zapata. Como veremos, este relato se ha transformado en una de las hipótesis a contrastar sobre el terreno, ya que por el momento se han obtenido resultados que no se condicen exactamente con lo que el relato indica.

En cuanto a los antecedentes de investigación se pueden mencionar los aportes de Strube Erdmann (1958, 1963), González (1966), Raffino et al. (1994) 
y Raffino (1995), quienes mediante el uso de fuentes históricas, etnohistóricas y arqueológicas sostienen la conexión entre El Shincal de Quimivil y Watungasta de Abaucán, y dan sustento a la posible ruta de Diego de Almagro hacia Chile.

A continuación, haremos hincapié en los sitios arqueológicos y elementos del paisaje que nos han permitido componer una de las rutas de comunicación a través del interfluvio de Zapata.

\section{Sitio Corralito}

A una distancia de 4,6 km en línea recta al suroeste de El Shincal, se halla el sitio Corralito, a una altura de $1.259 \mathrm{msnm}$, dentro de un espeso monte espinoso. Se trata de un antiguo puesto de ocupación transitoria, actualmente abandonado, donde se encuentra una gran reserva de agua para abastecer a los animales que pastorean por la zona. La particularidad de este punto de interés es la presencia de grandes rocas alineadas colocadas de forma irregular que delimitan un espacio amplio que podría haber funcionado como corral, tal como sucede en la actualidad. Otros hallazgos para destacar son los restos de qhonanas, morteros múltiples y muros de piedras bajos en mal estado de conservación. En cuanto al material en superficie, se recuperaron fragmentos de vidrio, desechos de talla y alfarería. Los análisis de la cerámica determinaron la presencia de pucos o escudillas Ciénaga y Aguada (gris, pintada y allpatauca), tinajas Belén Negro sobre Rojo, aríbalos/ aribaloides Inca Provincial y vasijas globulares utilitarias (Moralejo 2011).

\section{Sitio Paraje La Aguada}

Continuando con el mismo rumbo suroeste y a solo 3,3 $\mathrm{km}$ en línea recta de Corralito, se localiza el sitio Paraje La Aguada. Este se asienta sobre el cono aluvial del río La Aguada o Vallecito a $1.331 \mathrm{msnm}$, por detrás de un conjunto de viviendas correspondiente a la población del lugar (fig. 5). Presenta un alto grado de perturbación debido a la utilización de sus rocas para confeccionar las viviendas actuales, el uso como depósito de basura y también como corral para cerdos domésticos.

El sitio está compuesto por recintos de piedra pequeños (R3) y medianos (R1 y R2), y espacios abiertos de tamaño mayor con paredes curvas y oblicuas al trazado general (EA1, EA2, EA3). La altura de los muros varía

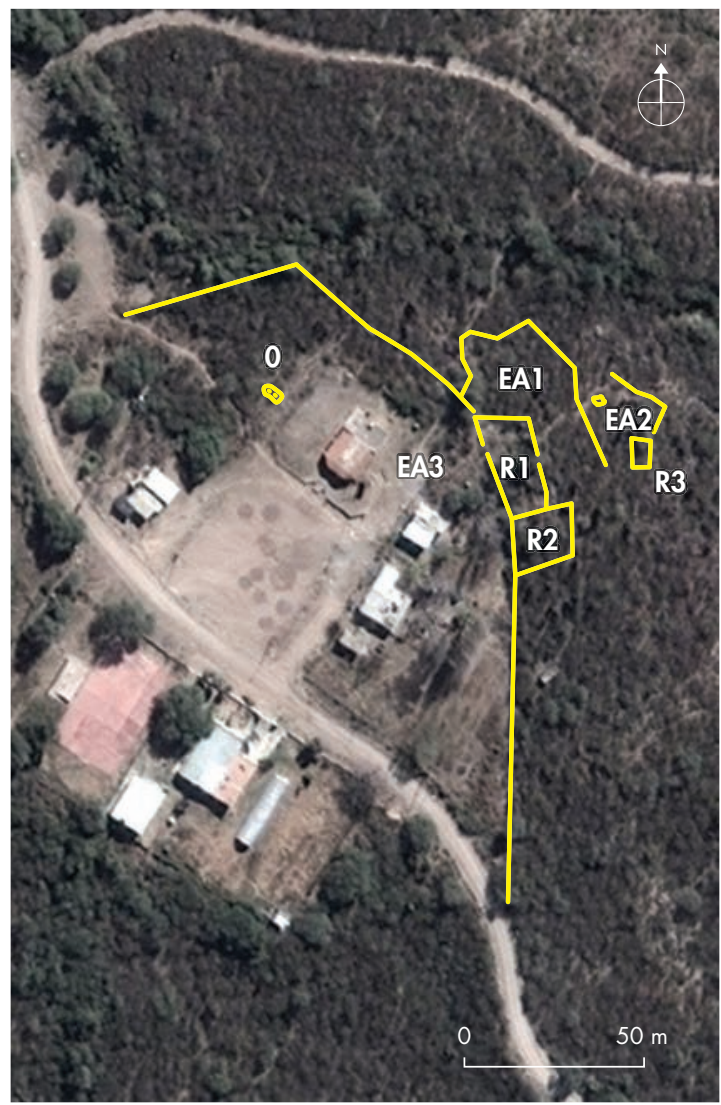

Figura 5. Plano del sitio Paraje La Aguada. $\mathrm{R}=$ recinto; $\mathrm{EA}=$ espacios abiertos; $\mathrm{O}=$ dos oquedades localizadas sobre un mismo soporte de granito. Figure 5. Map of site Paraje La Aguada. R="recinto" (enclosure); $E A=$ "espacios abiertos" (open spaces); $O=$ two cavities localized on a single granite support.

de 0,50 a $2 \mathrm{~m}$ y se han registrado diferentes técnicas constructivas. Los recintos medianos están construidos con pirca doble sin mortero, cuyo ancho oscila entre 0,90 y $1,15 \mathrm{~m}$. Están conformados por rocas graníticas seleccionadas y canteadas de diversos tamaños. También se han aprovechado grandes bloques rocosos como cimientos de algunos recintos (fig. 6). Algunas paredes demuestran un máximo cuidado en la técnica constructiva, ubicando de manera preferencial las caras planas de las rocas hacia el interior del recinto. Otras presentan un relleno interno de piedras de menor tamaño. Por otro lado, los espacios abiertos están construidos con muros dobles de 0,80 a $0,90 \mathrm{~m}$ de ancho, conformados por rodados del río y piedras seleccionadas. En cuanto al $\mathrm{R} 3$, este posee una pared doble de rodados cementadas con mortero de barro. 


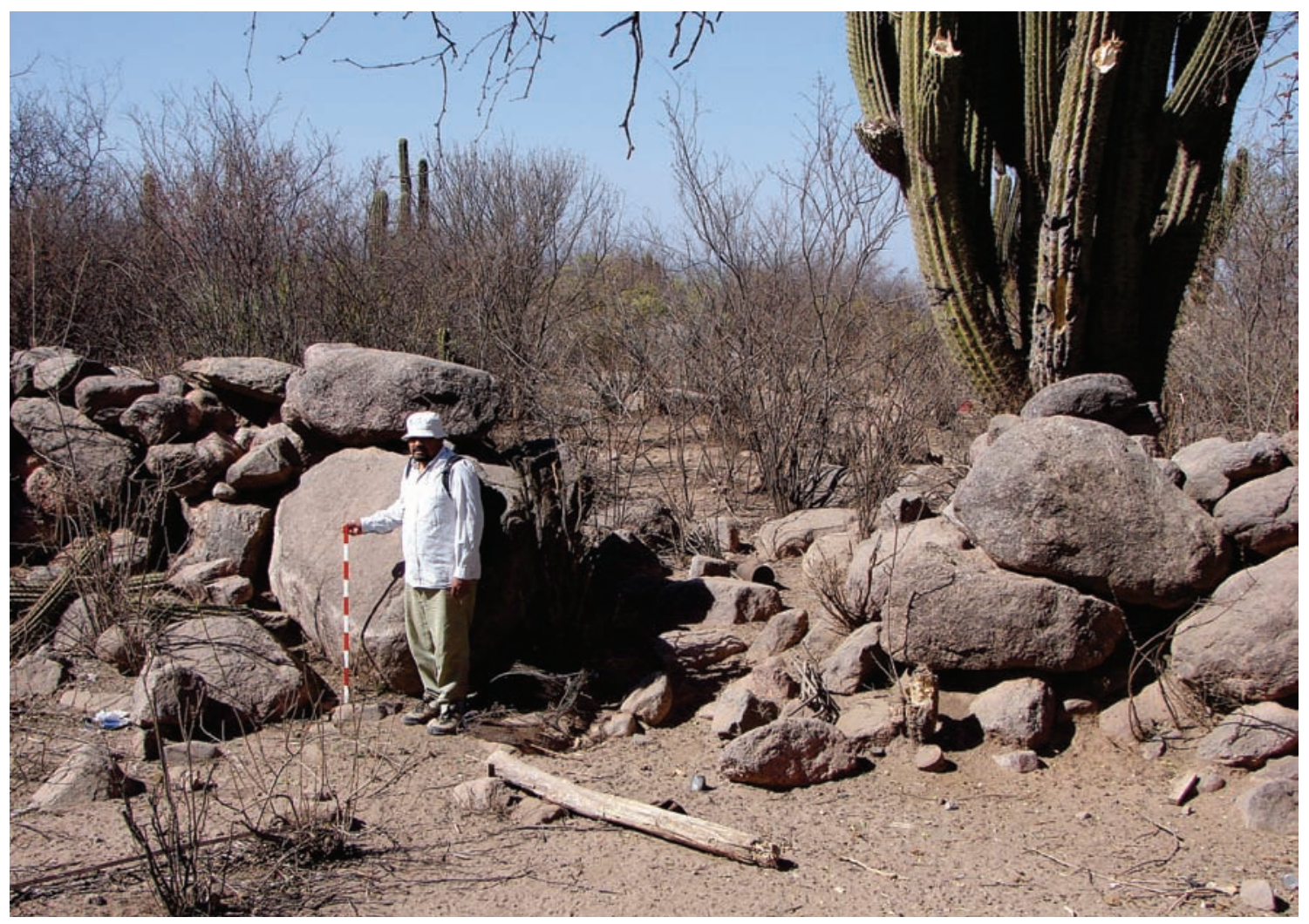

Figura 6. Pared oriental, con vano de acceso, correspondiente al Recinto 1 del sitio Paraje La Aguada. Figure 6. East wall with point of access, in the Recinto 1 of the site Paraje La Aguada.

Otros hallazgos asociados han sido oquedades con evidencias de pulido interno dispuestas sobre grandes bloques de granito. No se han encontrado materiales cerámicos en superficie, lo que dificulta establecer algún tipo de aproximación cronológica (Moralejo 2011).

A modo de hipótesis y por semejanza con algunos sitios correspondientes al Período Tardío o Desarrollos Regionales (900-1470 DC) del valle de Hualfín creemos que el patrón de asentamiento -recintos subrectangulares asociados a espacios abiertos irregulares- observado en el Paraje La Aguada podría corresponder a viviendas comunicadas con grandes espacios comunitarios. En este sentido, vale destacar que la técnica de construcción presente en los espacios abiertos (EA1, EA2 y EA3) es semejante a la observada en los muros de Corralito. En cuanto a las diferencias constructivas de los recintos, por el momento no podemos establecer si se debe a diferencias temporales en su construcción u ocupación, a la presencia de diferentes manos de obra o al resultado de requerimientos funcionales específicos.
Por otro lado, la ausencia de cerámica en superficie es un dato significativo que lleva a plantear otra hipótesis: recintos que posiblemente funcionaban como corrales. La larga alineación semicircular de rocas (que delimita el EA3) quizás permitía concentrar con mayor facilidad los animales para posteriormente ser introducidos en los respectivos corrales. En este sentido, la presencia de oquedades (e.g. dos de ellas se sitúan sobre un mismo soporte de granito semienterrado) podría estar relacionada con espacios donde se efectuaban diferentes tipos de ofrendas propias de la mesa o missa andina (Flores Ochoa 1997; Matos Mendieta 2009, comunicación personal).

Aproximadamente a unos 2,7 km en línea recta del Paraje La Aguada, manteniendo el mismo rumbo sur-oeste y paralelo a la antigua Ruta Nacional $N^{\circ} 40$, se identificó, gracias a un poblador, un rasgo lineal de $1,1 \mathrm{~km}$ de largo conformado por un talud y excavación ladera dentro. Si bien en la actualidad es utilizado de manera ocasional como un camino, nuestra hipótesis 


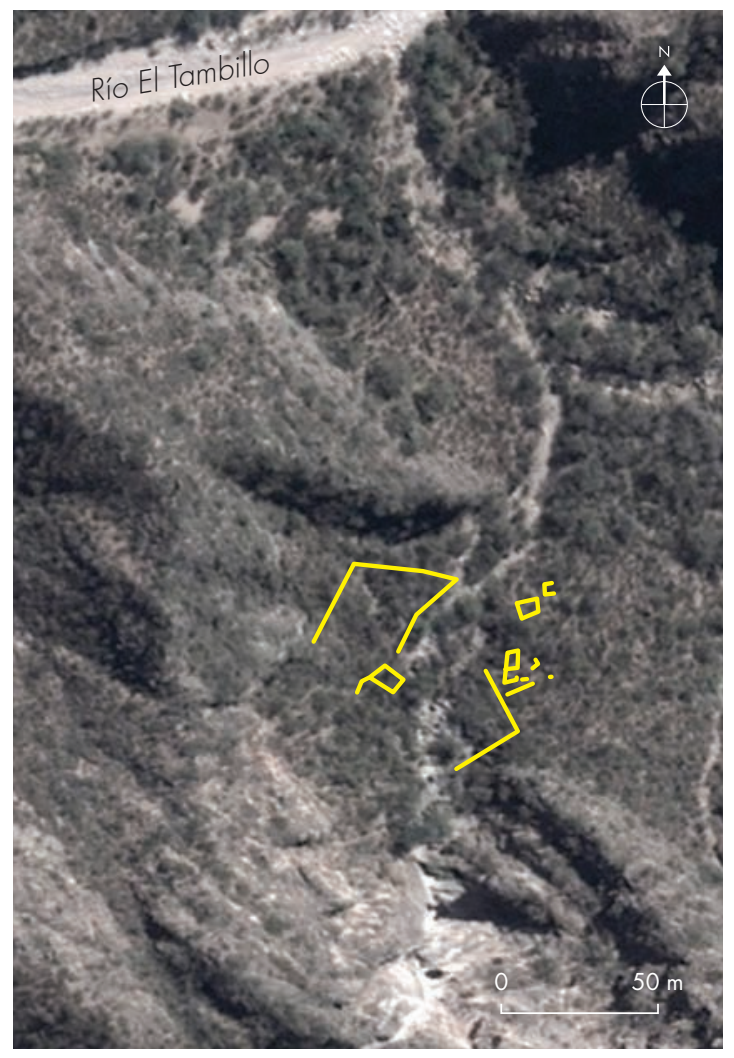

Figura 7. Plano del sitio Tambillo Viejo. Figure 7. Map of site Tambillo Viejo.

sostiene que se trataría de una antigua acequia que ha sido transformada y utilizada para el tránsito (Moralejo 2011).

\section{Tambillos de Zapata}

Con esta denominación se hace referencia a dos sitios arqueológicos localizados al sur-oeste del Paraje La Aguada. Uno de ellos se denomina Tambillo Viejo y se encuentra ubicado en la base de un cerro dentro de una pequeña quebrada lateral al río El Tambillo (fig. 7). Durante las tareas de prospección se pudo constatar una ocupación relativamente reciente, a juzgar por la presencia de un corral de ramas, restos de botellas de vidrio y plástico y una construcción de adobe muy deteriorada. Se hallaron también recintos de pirca doble -con piedras canteadas y altamente seleccionadas- rellenos con mortero de barro, vanos de acceso y unidades de molienda múltiples. Algunos muros son simples y están compuestos por rodados del río (Moralejo 2011). No se ha hallado cerámica en superficie, razón por la cual no ha sido posible determinar su profundidad temporal hasta tanto no realizar excavaciones sistemáticas y estudios arquitectónicos más detallados.

En la cima del cerro donde se emplaza este sitio se halló un hito caminero muy particular dentro de esta ruta (Moralejo 2011). Se trata de una roca aparentemente natural altamente visible desde diversos puntos del paisaje (fig. 8). Es bien conocida dentro de la cosmovisión andina la carga simbólica que tenían determinados rasgos naturales del paisaje (Hyslop 1990; Farrington 1992). Por esta razón, creemos que esta roca pudo constituir un verdadero hito o mojón caminero con un fuerte carácter de señalización, teniendo en cuenta su altura y visibilidad. También es posible, y no por ello excluyente, considerar la esfera ritual y simbólica en la que este rasgo tan peculiar pudo estar involucrado (Sanhueza 2004), razón por la cual consideramos que podría tratarse de una roca waka.

A menos de $2 \mathrm{~km}$ del Tambillo Viejo se emplaza el sitio Tambillo Nuevo, sobre el piedemonte oriental de la sierra de Zapata, hacia ambos lados del cauce seco del río El Tambillo (fig. 9). Entre el Tambillo Nuevo y El Shincal media una distancia en línea recta no superior a los 17 $\mathrm{km}$, lo que podría equivaler a media jornada de viaje. El sitio Tambillo Nuevo está compuesto por dos sectores denominados Conjuntos I y II, uno emplazado sobre una terraza de baja altura correspondiente a la margen derecha -aguas arriba- del río El Tambillo y el otro sobre la terraza opuesta de mayor altura. En términos generales, posee un diseño ortogonal conformado por recintos perimetrales compuestos (RPC) cuya técnica constructiva mantiene el canteado de las piedras, la verticalidad y linealidad típica de las construcciones incaicas (fig. 10). El análisis del material cerámico recuperado en superficie y en excavaciones señala la presencia de alfarería Inca Provincial con una alta predominancia de aríbalos/aribaloides. También, se ha recuperado por fuera de los Conjuntos I y II una alta proporción de cerámica Temprana, principalmente Ciénaga correspondiente a escudillas o pucos, y cerámica Aguada Allpatauca correspondiente a vasijas globulares. Entre los dos conjuntos anteriormente mencionados corre un segmento de camino incaico de $5 \mathrm{~m}$ de ancho correspondiente al tipo despejado y amojonado dispuesto sobre una superficie de arena y rocas (fig. 11).

En el Tambillo Nuevo se habrían realizado múltiples actividades vinculadas con el alojamiento de personas, control vial, reaprovisionamiento de las 


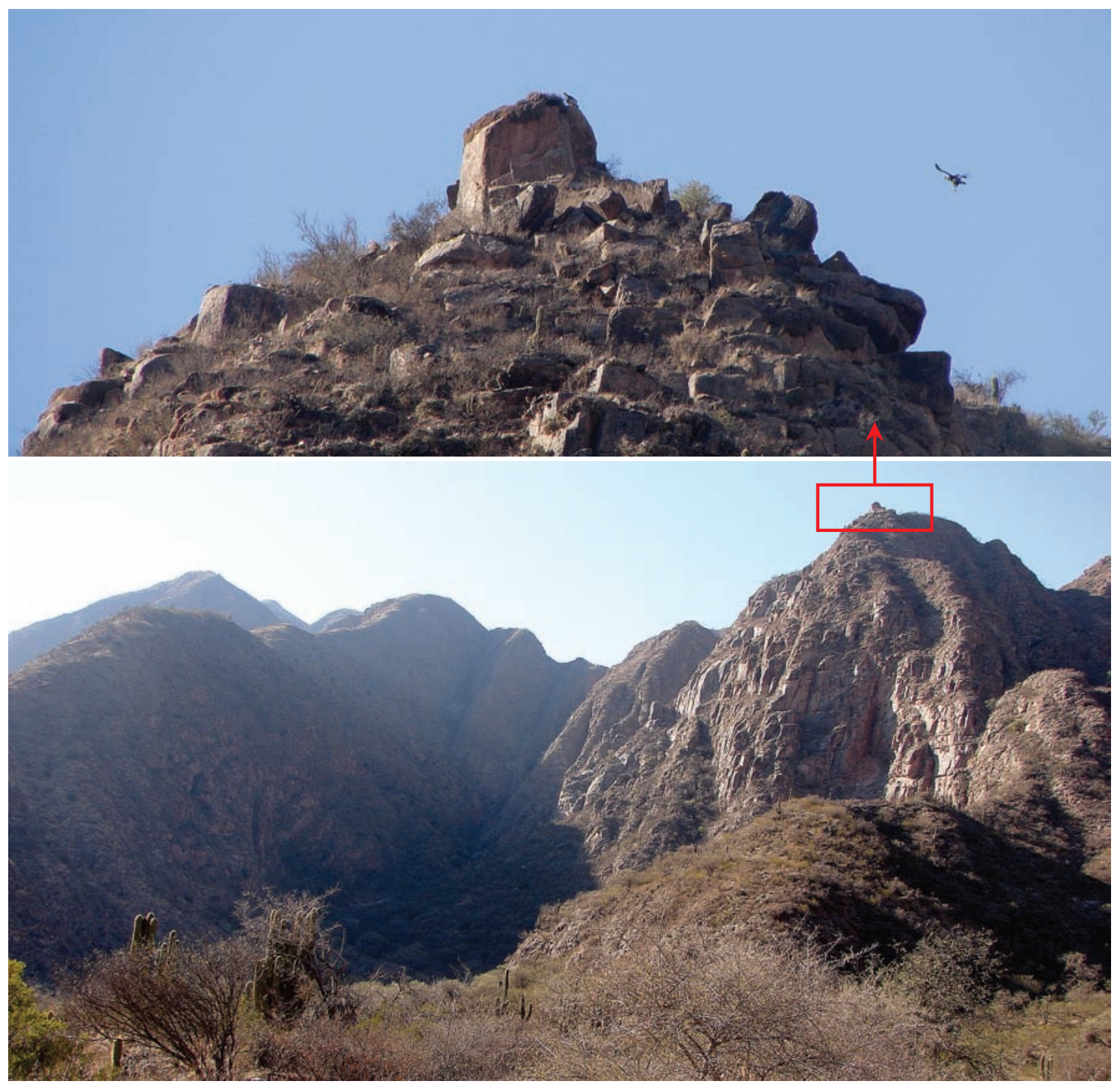

Figura 8. Gran roca sobre la cima del cerro. Figure 8. Large rock on the summit of a hill.

caravanas en tránsito e incluso con aspectos ceremoniales (Moralejo 2009, 2011).

Muy próximo al Tambillo Viejo y Tambillo Nuevo, y dentro de dos pequeñas quebradas laterales al río El Tambillo, se han hallado sendos saltos y cuerpos de agua naturales asociados con oquedades cuyas superficies internas están bien pulidas. Uno de estos contextos, ubicado próximo al sitio Tambillo Nuevo, es conocido por los pobladores locales como Pozo de la Rubia. Resulta muy significativa la semejanza entre ambos espacios sobre todo si pensamos en la importancia que poseían las rocas y el agua para los incas (Brown 1998). Si a esto le sumamos la presencia de las oquedades y la visibilidad hacia la quebrada del río El Tambillo podríamos estar frente a un contexto muy particular vinculado con actividades de fuerte connotación ritual (figs. 12-13).

La ruta continúa hacia el sur-oeste de los Tambillos de Zapata y atraviesa la cuesta de Zapata hasta finalmente salir de la serranía homónima. ${ }^{2}$ Inmediatamente, se desplaza hacia el occidente por la quebrada Abra del Paraguay hasta conectarse con el sitio chasquihuasi de Anillaco y comenzar su descenso al valle de Abaucán (fig. 14). Desde el Tambillo Nuevo se calculan dos jornadas de viaje hasta arribar al sitio de Watungasta. 


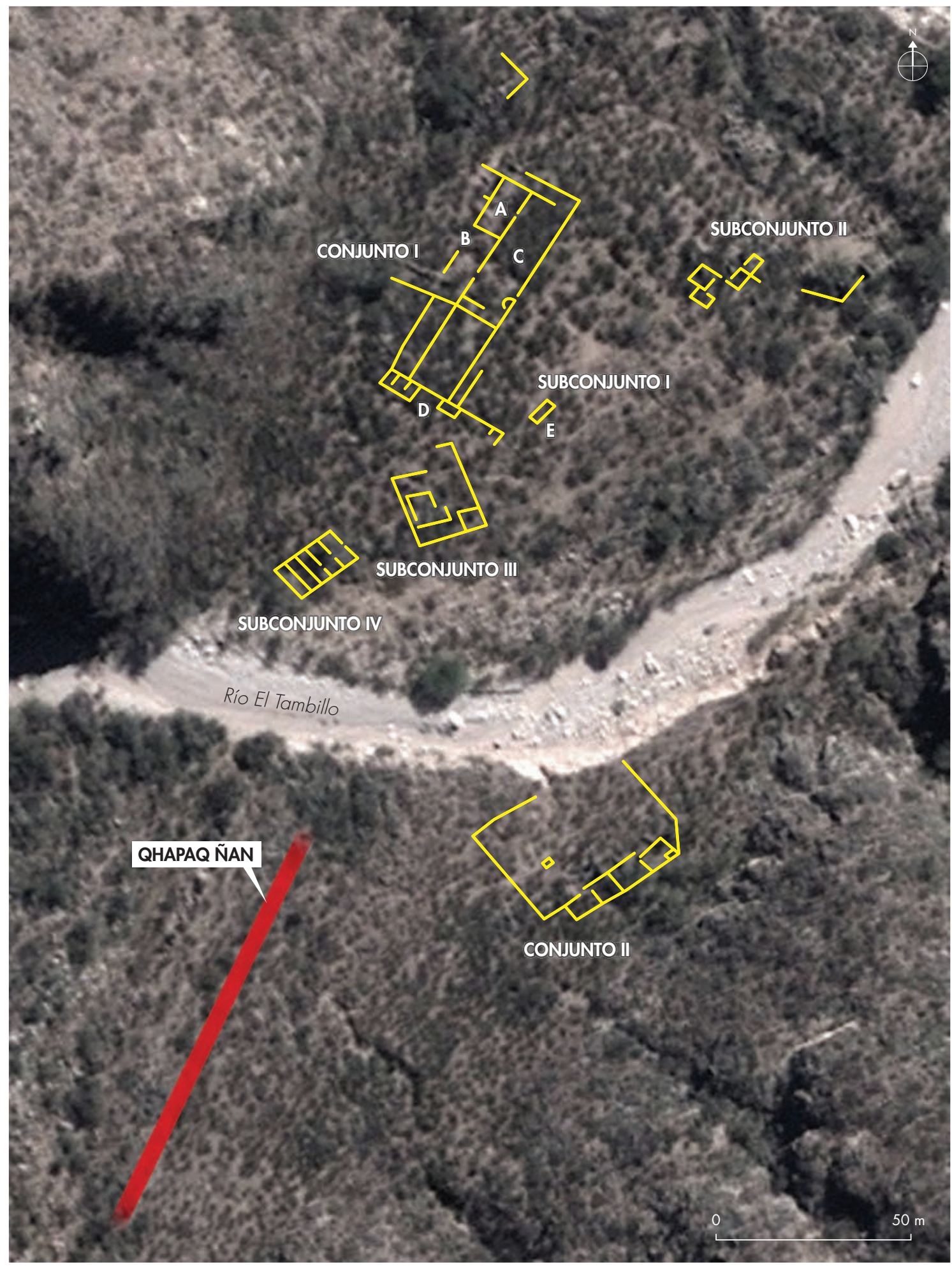

Figura 9. Plano del sitio Tambillo Nuevo. Figure 9. Map of site Tambillo Nuevo. 


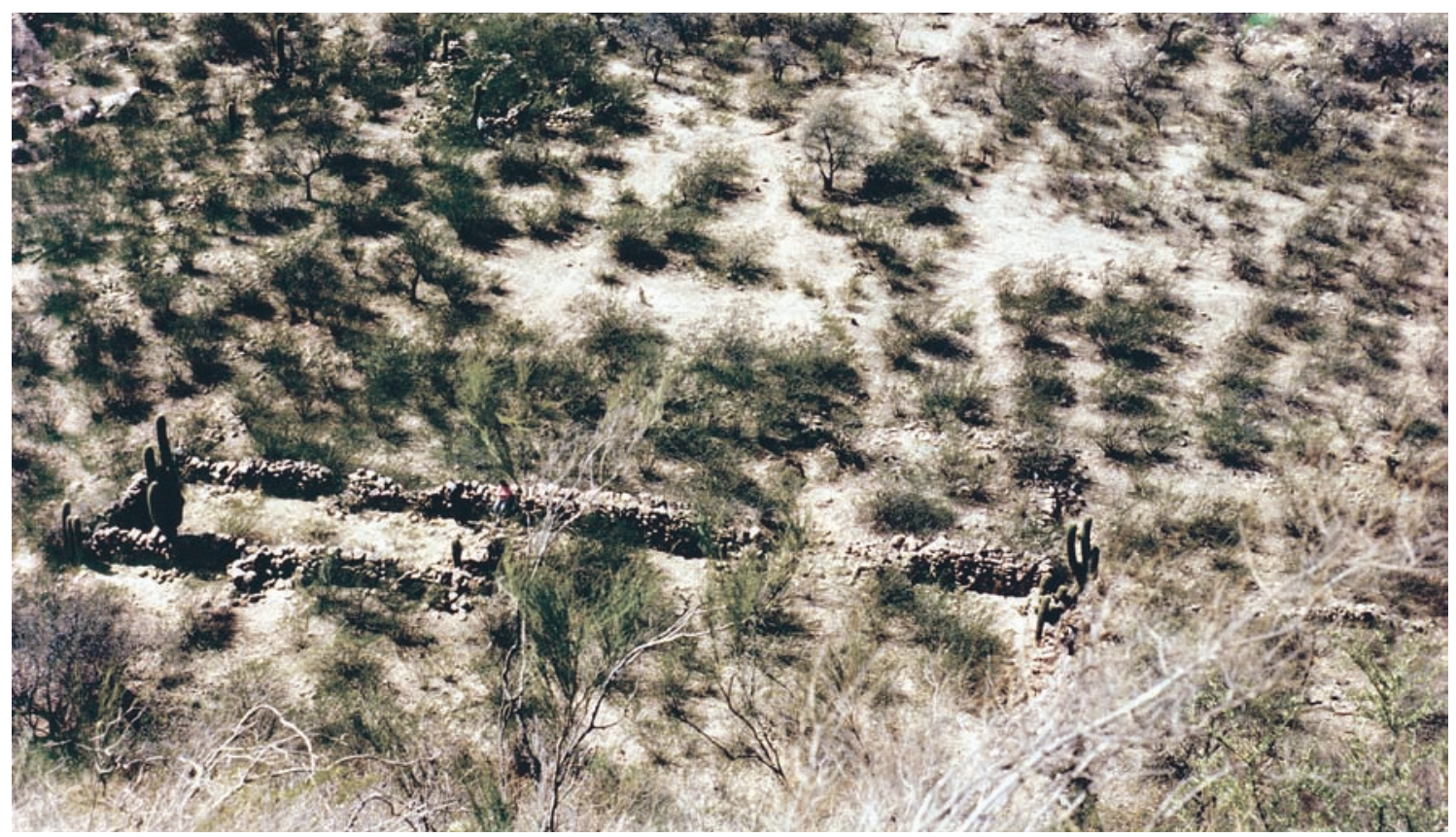

Figura 10. Imagen parcial del sector donde se emplaza el Conjunto I del sitio Tambillo Nuevo (tomada de Raffino et al. 2008: 320, figura 5). Figure 10. Partial image of the sector where Conjunto I is located in the Tambillo Nuevo site (in Raffino et al. 2008: 320, Figure 5).

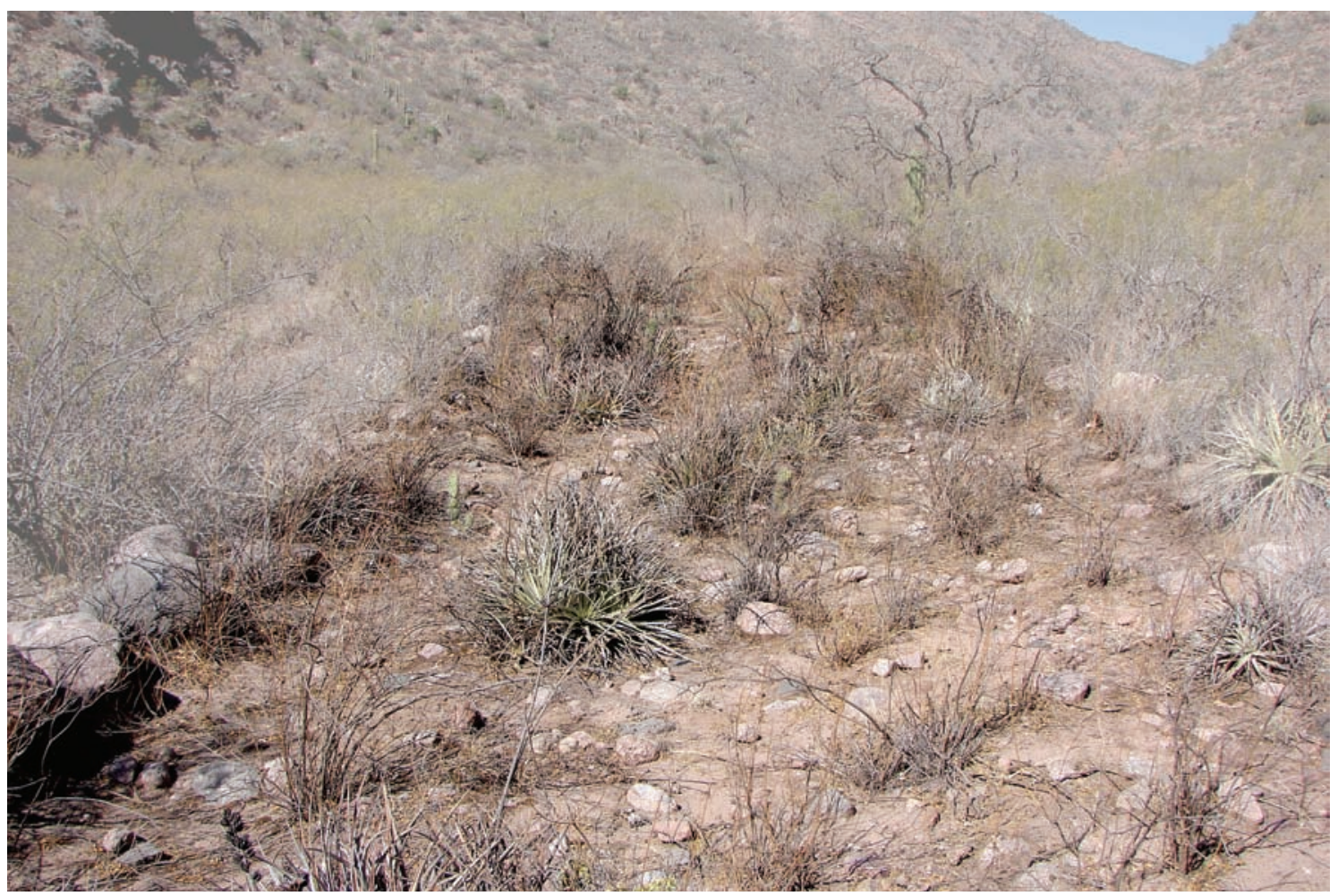

Figura 11. Segmento de camino incaico correspondiente al tipo despejado y amojonado. Figure 11. Segment of the Inca road, cleared and with boundaries marked by stones. 

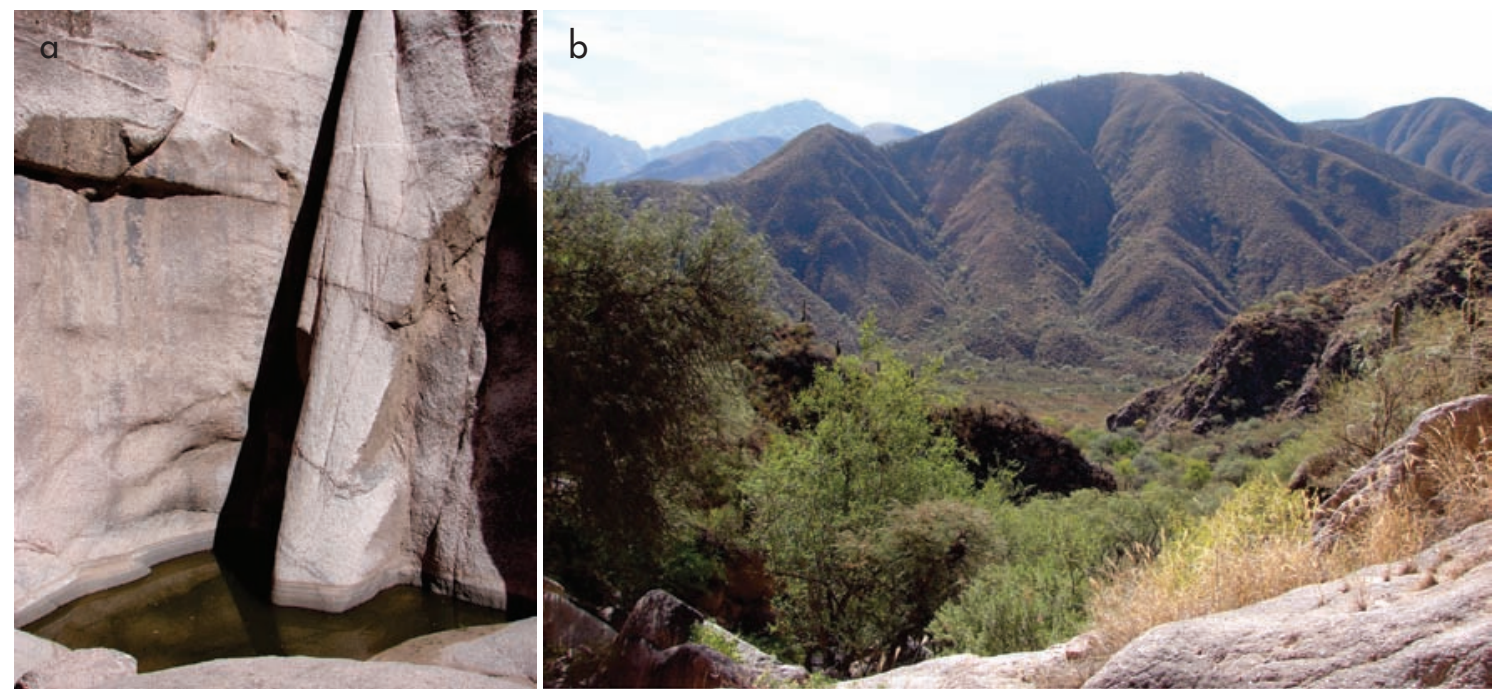

Figura 12: a) salto y cuerpo de agua en el sitio Tambillo Viejo; b) visibilidad hacia el fondo de quebrada del río El Tambillo. Figure 12: a) waterfall and body of water in the site of Tambillo Viejo; $b$ ) visibility toward the end of the El Tambillo ravine.
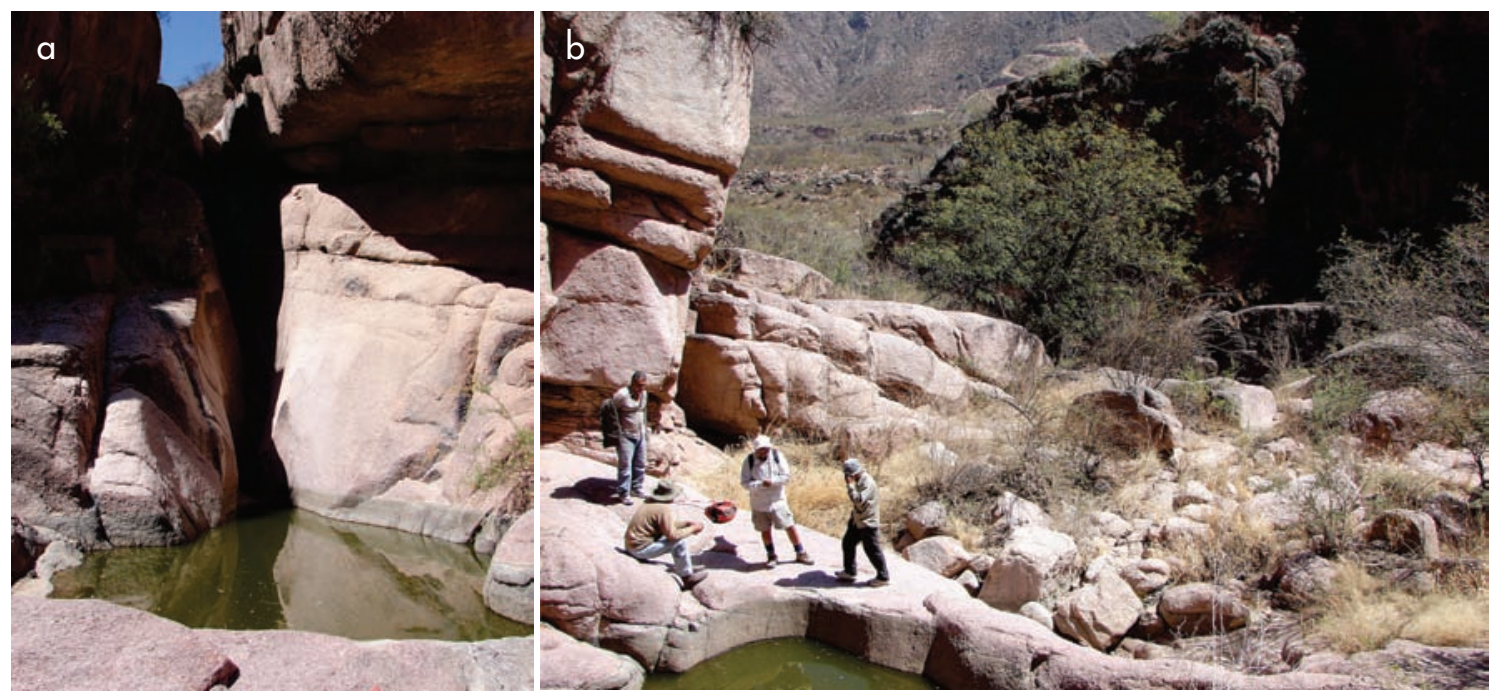

Figura 13: a) salto y cuerpo de agua en el sitio Tambillo Nuevo; b) visibilidad hacia el fondo de quebrada del río El Tambillo. Figure 13: a) waterfall and body of water in the site of Tambillo Nuevo; $\boldsymbol{b}$ ) visibility toward the end of the El Tambillo ravine.

\section{CONSIDERACIONES FINALES}

Cuando hablamos de nuestro objeto de estudio, el uso de los caminos y senderos a lo largo del tiempo, lo hacemos teniendo en cuenta el medio que lo rodea, de modo que pensamos en un paisaje que se presenta como socialmente construido. El estudio no es solo de los caminos per se, sino también de sus constructores, de las técnicas empleadas y de los usuarios (Herrera
\& Cardale de Schrimpff 2000). Es decir, el camino no es un espacio exclusivamente dedicado al transporte, sino también un lugar donde se reflejan las creencias y sistemas de valores de la sociedad.

Los resultados de las investigaciones en el interfluvio de la sierra de Zapata señalan la presencia de diferentes tipos de asentamientos con determinadas características arquitectónicas, modo de instalación, materiales recuperados y relación con el ambiente. Teniendo en 
cuenta esta evidencia arqueológica y su proximidad con los valles calchaquíes, la puna y el campo de BelénAndalgalá, no hay duda que esta sierra constituyó una importante ruta de comunicación entre los valles de Hualfín y Abaucán, situación que habría generado una dinámica sociocultural muy intensa, propia de zonas internodales (Núñez \& Nielsen 2011).

En cuanto a los asentamientos mencionados, es necesario continuar con las investigaciones en los sitios Corralito, Paraje La Aguada y Tambillo Viejo con el propósito de determinar su profundidad temporal y el rol que tuvieron dentro de esta ruta. Sin embargo, de acuerdo a los estilos alfareros hallados en Corralito y Tambillo Nuevo, creemos que el área ha tenido una ocupación intensa y multicomponente cuyo tránsito podría extenderse al Período Temprano (500 AC-400 DC). Esta hipótesis también se ve favorablemente contrastada con la presencia de otros sitios correspondientes a los Períodos Temprano (ocupación Saujil y Ciénaga) y Medio (ocupación Aguada) en la cuesta de Zapata (Sempé 1973, 1976; González \& Sempé 1975).

En cuanto a las evidencias de la ocupación incaica, estas son muy notables y particulares en el centro político, administrativo y ceremonial de El Shincal de Quimivil, en el tambo de enlace Tambillo Nuevo y en el pequeño chasquihuasi de Anillaco. Allí hemos visto que el camino registra diferentes técnicas de planificación y construcción y se encuentra asociado a otros puntos de interés o elementos sagrados de la cosmovisión andina como las grandes rocas tokankas que demarcan el camino de El Shincal; los sendos cuerpos de agua casi idénticos de los Tambillos de Zapata y la gran roca waka a manera de mojón y/o tokanka en el Tambillo Viejo. Para el momento inca, todos estos rasgos modelaban y representaban un paisaje vial integrado con alto contenido simbólico que era producto de un dominio territorial de acuerdo a una determinada racionalidad espacial y cultural. Sin duda, esta ruta continuó en uso y adquirió un rol relevante durante el Período Inca (1570-1536 DC) del NOA, conectando dos centros nodales de importancia como El Shincal de Quimivil y Watungasta de Abaucán. Fue en ese momento donde quizás sufrió una reformulación material e ideológica acorde con el proyecto político de expansión, lo que provocó una intensificación sistemática del tráfico y la comunicación interregional.

Posteriormente, siguió siendo utilizada durante las épocas Colonial y Republicana. Testimonio de ello es el viaje que realizó en 1712 el maestre de campo Juan

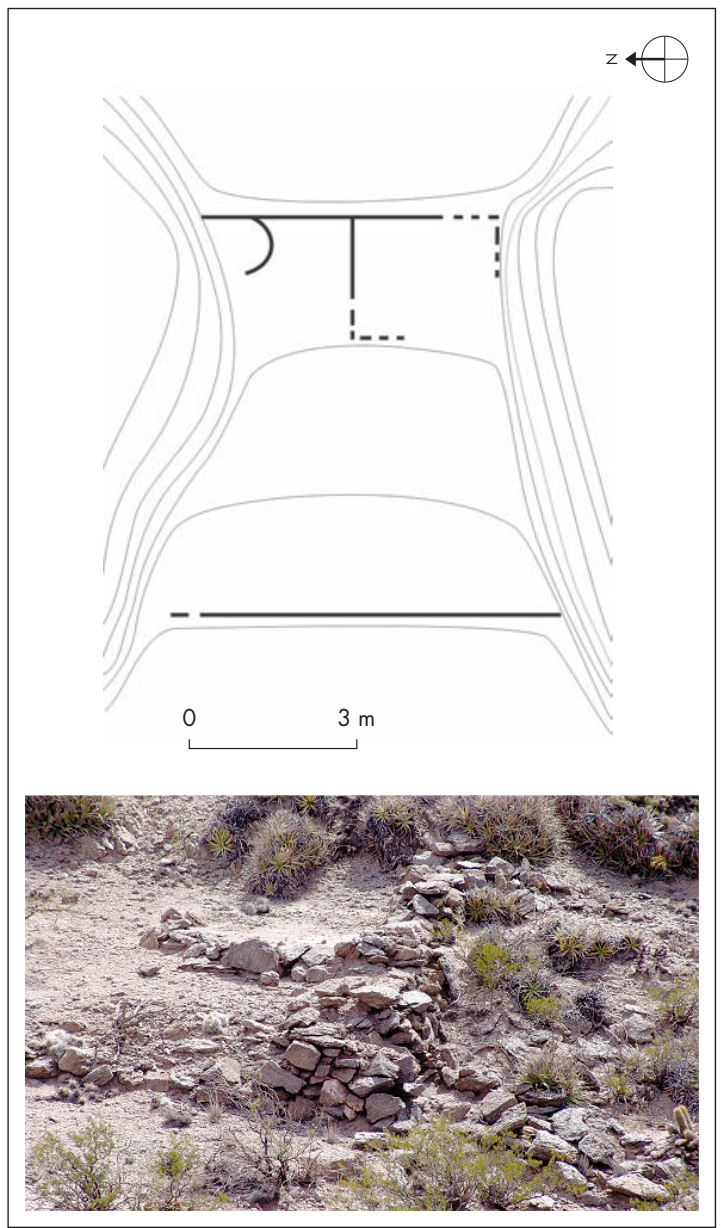

Figura 14. Plano del sitio Anillaco (tomado de Raffino et al. 2008: 320, figura 5). Figure 14. Map of the site of Anillaco (in Raffino et al. 2008: 320, Figure 5).

Gregorio Bazán de Pedraza, encomendero de Fiambalá y Tinogasta con residencia en Anillaco, cuando se dirigía a hacerse cargo de la Gobernación del Paraguay (Raffino et al. 2008). En tiempos más recientes, también ha constituido la única vía de paso que permite transponer rápidamente la serranía y comunicar los Departamentos de Belén y Tinogasta, favoreciendo el arreo de animales y el flujo de información.

Por último, consideramos importante continuar con los trabajos en la sierra de Zapata para avanzar en el estudio de las prácticas sociales vinculadas con los asentamientos que jalonan esta ruta pensando en la importancia del tráfico caravanero como modelo de complementariedad para comprender la dinámica social y cultural del área. 
RECONOCIMIENTOS A los organizadores del Taller "Qhapaq Ñan I" por la invitación a participar en las exposiciones realizadas durante el mes de marzo de 2015 en San Pedro de Atacama, Chile. Al Consejo Nacional de Investigaciones Científicas y Técnicas, la Agencia Nacional de Promoción Científica y la Universidad Nacional de La Plata por el financiamiento. A la Municipalidad de Londres, Secretaría de Estado de Cultura de Catamarca, Dirección Provincial de Antropología de Catamarca, comunidad de Londres y Belén y a nuestros compañeros de la División de Arqueología del Museo de La Plata por su apoyo constante durante las tareas de campo y gabinete. Al Lic. Diego Gobbo por su colaboración incondicional en la preparación de las imágenes. A nuestro gran querido maestro, el Dr. Rodolfo A. Raffino, quien desde un primer momento confió en nosotros y nos brindó todo su apoyo y entusiasmo para llevar a cabo nuestros objetivos. A los editores y evaluadores del Boletín del Museo Chileno de Arte Precolombino.

\section{NOTAS}

${ }^{1}$ Se trata de una denominación dada al comienzo de las investigaciones, por lo que está sujeta a cambios en tanto las mismas avancen.

${ }^{2}$ En la actualidad se están realizando nuevas investigaciones en la cuesta de Zapata, con resultados muy satisfactorios vinculados con la vialidad incaica.

\section{REFERENCIAS}

Anschuetz, K.; R. Wilshusen \& C. Scheick, 2001. An archaeology of landscapes: perspectives and directions. Journal of archeological research 9 (2): 157-211.

Berenguer, R.; I. Cáceres, C. Sanhueza \& P. Hernández, 2005. El Qhapaqñan en el Alto Loa, norte de Chile: un estudio micro y macromorfológico. Estudios Atacameños 29: 7-39.

Brown, D., 1998. Water and power in the provinces: water management in inka centers of the central highlands of Peru. Tawantinsuyu 5: 53-59, Canberra.

BRUCH, C., 1911. Exploraciones arqueológicas en las Provincias de Tucumán y Catamarca. Revista del Museo de La Plata XIX, Buenos Aires.

Capparelli, A., 1997. Reconstrucción ambiental de la instalación arqueológica inka de El Shincal. Tesis para optar al grado de Doctora en Ciencias Naturales, Facultad de Ciencias Naturales y Museo, Universidad Nacional de La Plata.

EARLE, T., 1991. Paths and roads in evolutionary perspective. En Ancient road networks and settlement hierarchies in the New World, C. D. Trombold, Ed., pp. 10-16. New York: Cambridge University Press.

FARrington, I., 1992. Ritual geography, settlement patterns and the characterization of the provinces of the Inka heartland. World Archaeology 23 (3): 368-385.
FARrington, I., 1999. El Shincal: un Cusco del Kollasuyu. En Actas del XII Congreso Nacional de Arqueología Argentina, C. Diez, Ed., tomo I, pp. 53-62, La Plata.

FARrington, I., 2013. Cusco. Urbanism and archaeology in the Inka world. Florida: University Press.

Flores OchoA, J., 1997. La missa andina. En Homenaje a María Rostworowski. Arqueología, antropología e historia en los Andes, R. Varon \& J. Flores, Eds., pp. 717-728. Lima: Instituto de Estudios Peruanos-Banco Central de Reserva del Perú.

FurQue, H., 1900. Las ruinas de Londres de Quimivil (Catamarca). Anales de la Sociedad Científica Argentina 50: 166-171, Buenos Aires.

Giovannetti, M., 2009. Articulación entre el sistema agrícola, sistema de irrigación y áreas de molienda como medida del grado de ocupación inka en El Shincal y Los Colorados (valle de Hualfín, Provincia de Catamarca). Tesis para optar al grado de Doctor, Facultad de Ciencias Naturales y Museo, Universidad Nacional de La Plata.

Giovannetti, M.; J. Spina; G. Cochero; G. Corrado; L. Aljanati \& M. Valderrama, 2012. Nuevos estudios en el sector 'Casa del Kuraka' del sitio El Shincal de Quimivil (Dpto. Belén, Prov. Catamarca, Argentina). Inka Llaqta 3 (3): 161-190, Lima.

González, A., 1966. Las ruinas del Shincal. En Actas del Primer Congreso de Historia de Catamarca, tomo III, pp. 15-28. San Fernando del Valle de Catamarca: Junta de Estudios Históricos de Catamarca.

GonzÁlez, A. \& M. Sempé, 1975. Prospección arqueológica en el Valle de Abaucán. Revista del Instituto de Antropología 2: 49-129. San Miguel de Tucumán: Facultad de Filosofía y Letras-Museo de Prehistoria y Arqueología.

Herrera, L. \& M. Cardale de Schrimpff, 2000. Los caminos de la continuidad y el cambio. En Caminos precolombinos: las vías, los ingenieros y los viajeros, M. Cardale de Schrimpff \& L. Herrera, Eds., pp. 6-12. España: Instituto Colombiano de Antropología e Historia.

Hyslop, J., 1990. Inka settlement planning. Austin: University of Texas Press.

HysLop, J., 1992. Qhapaq Ñan. El sistema vial inkaico. Lima: Instituto Andino de Estudios Arqueológicos-Petróleos del Perú.

IgARETA, A., 2008. Últimas noticias desde Londres. El sitio histórico más antiguo de la arqueología de Catamarca. Tesis para optar al grado de Doctor en Ciencias Naturales, Facultad de Ciencias Naturales y Museo, Universidad Nacional de La Plata.

IGARETA, A., 2009. La redefinición del espacio construido como indicador de superposición entre instalaciones indígenas e hispánicas durante el Período Colonial. En América antigua. Arquitectura, arqueología y paisaje, J. Buján, Comp., pp. 145173. Buenos Aires: Nobuko.

Moralejo, R., 2009. El “Tambillo Nuevo" de la sierra de Zapata (Provincia de Catamarca). Arqueología 15: 207-215. Buenos Aires.

Moralejo, R., 2011. Los Inkas al sur del valle de Hualfín: organización del espacio desde una perspectiva paisajística. Tesis para optar al grado de Doctor en Ciencias Naturales, Facultad de Ciencias Naturales y Museo, Universidad Nacional 
de La Plata <http://sedici.unlp.edu.ar/handle/10915/5242> [Citado 25-11-15].

Moralejo, R. \& M. Aventín, 2015. Los estudios de vialidad en El Shincal de Quimivil. En Una capital Inka al sur del Kollasuyu: El Shincal de Quimivil, R. Raffino, L. Iácona, R. Moralejo, D. Gobbo \& M. Couso, Eds., pp. 105-125. Buenos Aires: Fundación de Historia Natural Félix de Azara.

Moralejo, R.; M. Couso, M. Iglesias \& M. Aventín, 2015. La expedición Benjamín Muniz Barreto a El Shincal de Quimivil (Londres, Catamarca). En Libro de Resúmenes del vi Congreso Nacional de Arqueología Histórica, p. 87. Mendoza: Facultad de Filosofía y Letras, Universidad Nacional de Cuyo.

Morlans, M., 1995. Regiones naturales de Catamarca. Provincias geológicas y provincias fitogeográficas. Revista de Ciencia y Técnica II (2): 1-41. San Fernando del Valle de Catamarca: Universidad Nacional de Catamarca.

NúÑEZ, L. \& A. E. Nielsen, 2011. Caminante, sí hay camino: Reflexiones sobre el tráfico sur andino. En En ruta: arqueología, historia y etnografía del tráfico surandino, L. Núñez \& A. Nielsen, Eds., pp. 11-41. Córdoba: Encuentro Grupo Editor.

Raffino, R., 1990. Poblaciones indígenas en Argentina. Urbanismo y proceso social precolombino. Buenos Aires: Tipográfica Editora Argentina.

RAFFinO, R., 1995. Inka Road research and Almagro's route between Argentina and Chile. Tawantinsuyu I: 36-45, Canberra.

Raffino, R., 1995-1996. El Shincal de Quimivil. Boletín de la Junta de Estudios Históricos de Catamarca XII: 203-228, San Fernando del Valle de Catamarca.

RAFFino, R., 2004. El Shincal de Quimivil. San Fernando del Valle de Catamarca: Sarquís.
Raffino, R.; R. Alvis, A. Manzo \& M. Toddere, 1994. Arqueología inka cordillerana y la expedición de Almagro. En Actas y Memorias del XI Congreso Nacional de Arqueología Argentina, Revista del Museo de Historia Natural, tomo XIII, n 1/4, pp. 196-199, San Rafael.

Raffino, R.; R. Moralejo \& D. Gobbo, 2008. El dominio Inka en la sierra de Zapata (NOA). Investigaciones y Ensayos 56: 309-332. Buenos Aires.

SANHuezA, C., 2004. Medir, amojonar, repartir: territorialidades y prácticas demarcatorias en el camino incaico de Atacama (II Región, Chile). Chungara 36 (2): 483-494, Arica.

SEMPÉ, M., 1973. Últimas etapas del desarrollo cultural indígena (1480-1690) en el valle de Abaucán, Tinogasta: Provincia de Catamarca. Revista del Museo de la Plata 50: 3-46. La Plata.

Sempé, M., 1976. Contribución a la arqueología del Valle de Abaucán, Departamento de Tinogasta, provincia de Catamarca. Tesis para optar al grado de Doctor en Ciencias Naturales, Facultad de Ciencias Naturales y Museo, Universidad Nacional de La Plata.

Strube Erdmann, L., 1958. La ruta de don Diego de Almagro en su viaje de exploración a Chile. Revista de la Universidad Nacional de Córdoba 1: 269-293, Córdoba.

Strube Erdmann, L., 1963. Vialidad imperial de los Incas. Serie Histórica xxxiII: 1-113. Córdoba: Facultad de Filosofía y Humanidades, Universidad Nacional de Córdoba.

Trombold, C., 1991. An introduction to the study of ancient New World road networks. En Ancient road networks and settlement hierarchies in the New World, C. D. Trombold, Ed., pp. 1-10. New York: Cambridge University Press.

VITRY, C., 2000. Aportes para el estudio de caminos incaicos. Tramos Morohuasi-Incahuasi. Salta-Argentina. Salta: Gofica. 